\title{
Sustainable Supply Chain Management in Retail Industry
}

\author{
Han Jun ${ }^{1}$, Guo Yi ${ }^{2}$ \\ ${ }^{1)}$ Department of logistics management. Beijing Technology and Business University, Beijing, China (hanjun@btbu.edu.cn) \\ ${ }^{2)}$ School of Economics. Beijing Technology and Business University, Beijing, China (xmguoyi@126.com)
}

\begin{abstract}
With the increasingly intense competition in the retail market and the higher expectations of consumer, it is difficult to assure the healthy and stable development of retail enterprises simply by enlarging the amount of sales . Therefore, effective cost control is an important method for the development of retail industry and reasonable supply chain management is a strategy choice for retail cost control. The traditional supply chain management attached too much importance on economic factors. However, it accumulated massive environmental and social problems and seriously affected the healthy and stable development of retail enterprises. This requires the idea of sustainable development be studied into supply chain management and sustainable supply chain management be carried on, which has a strategic significance for the development of each main enterprise of retail industry. Based on the characteristics of retail industry, this paper analyses the necessity of implementing sustainable supply chain management, and points out deficit of the traditional retail chain management .It provides the theoretical basis for proper sustainable supply chain management and thus give polices to reshape the supply chain management.
\end{abstract}

Keywords - sustainable supply chain, retail industry, strategy

\section{零售业的可持续供应链管理}

\author{
韩军 $^{1}$ 郭毅 $^{2}$ \\ 1) 北京工商大学后勤管理处，北京 $100048 ， 中$ 国 \\ 2) 北京工商大学经济学院, 北京 100048 , 中国
}

摘 要 随着零售业市场竞争的日趋激烈, 消费者期望的提高, 简单的依靠扩大销售额很难保证零售企业的稳定健康发展。因此, 有效控制成本是零售业发展的重要途径。而合理的供应链管理是零售业控制成本的战略选择。传统的供应链管理过于偏重经济方面, 积累了大量的环境和社会问题, 严重影响了企业的稳定健康发展。这就要求把可持续发展理念贯穿到供应链管理中, 实施可持续的供 应链管理, 这对于零售业供应链各主体企业的发展具有战略意义。本文结合零售业特点, 对实施可持续供应链管理的必要性做出分析, 提出了零售业传统供应链管理的不足, 为确立正确的可持续供应链管理提供理论依据, 并依此提出了重塑供应链管理的策略。

关键词 可持续供应链, 零售业, 战略

1. 引言

供应链管理兴起的主要原因在于企业所面临的市场环 境发生了巨大转变: 由过去供应商主导的、静态的、简单 的市场环境变成了现在消费者为主导的、动态的、复杂的 市场环境。传统的企业各部门各组织之间缺少有效的信息 沟通和集成，相互独立管理，这种缺乏系统性和综合性的 企业运作模式已经无法适应新的市场环境, 因此企业必须 从全局和整体角度考虑产品的竞争力, 使供应链从一种运 作性的竞争工具上升为一种管理性的方法体系, 这是供应
链管理提出的实际背景(沈厚才, 2000)。进入 21 世纪以来, 经济全球化和企业竞争的加剧, 以及资源环境和社会问题 的日益突出, 可持续发展已被许多企业纳入战略理念。只 有那些既能提供公众认可度高而又对环境无害和的产品的 供应链, 才会有可持续的竞争力和随之而来的经济效益。 曾经对英国五家大公司进行研究调查的结果表明, 通过采 取一些对环境无害的方法, 供应链确实能够从中获利。与 此同时, 家乐福、沃尔玛等涉嫌价格欺计以及高额进场费 等频发的社会责任危机, 也表明了供应链企业盲目追求经 
济利润最大化目标和作为企业公民应负社会责任的割裂。 近年来, 有环境和社会责任意识的消费者的数量随着经济 不断的加速发展越来越多。现在, 无论是来自消费者的压 力, 还是来自投资市场对一个公司表现的关注, 都使得承 担企业社会责任、促进可持续发展成为现代企业的经营法 则之一。零售业因为一端直接面对消费者, 另一端连接制 造商或供应商, 是商贸流通领域的主体与核心, 同时也是 一个高度依赖供应链的行业, 因此提升其供应链管理业绩、 建立可持续供应链管理显得尤为必要。

\section{2. 相关文献综述}

最早研究可持续供应链起始于上世纪 90 年代, Drumwrigt（1994）提出了企业应该具有社会责任意识来组 织购买、生产、消费, 同年 Murphy 提出了在物流管理中 要注重环境问题。在可持续方面, Elkington (1998) 首先 提出企业追求自身发展的过程中, 需要同时满足经济、环 境、社会三重底线（Triple Bottom Line）的平衡。Linton (2007) 等人提出了可持续性与供应链的衔接和延进。

Craig R.Carte 和 Dale S.Rogers（2008）界定了可持续供应 链管理的定义: 为增加企业和企业所在的供应链的长期经 济效益, 通过系统协调跨组织的核心业务流程, 对组织的 社会、环境和经济目标进行战略的、透明的集成和实现。

可持续供应链管理作为一个新兴的理论出现并且在各 个行业和领域引起学者广泛的研究兴趣, 但如何将可持续 供应链管理与零售业两者真正的融合将是今后研究的重 点。由于可持续供应链管理在我国的研究只是处于起始阶 段, 还没有达成统一的共识。目前国内研究的重点主要集 中在可持续供应链管理内涵上, 未能突破上述可持续供应 链管理概念。

对于零售业供应链管理, 国内外学者都从不同角度进 行了研究和探讨。同时也认识到了传统供应链管理的不足, 提出了对零售业供应链管理的修正和再构。吴锦峰 (2007) 认为从战略的视角来研究零售业供应链管理是现实环境变 迁和研究发展的需要。David Simchi-Levi (2004) 等人对零 售商与供应商之间的关系进行了研究, 归纳了零售商— 供应商伙伴关系的主要特征, 提出了分销商一体化的理论。 晋雪莲 (2004) 认为零售企业加强供应链管理应从企业内 部着手, 有必要树立合作观念, 改善业务流程; 同时零售 企业也要关注其所在供应链包含的节点数及其在供应链上 的定位。Roberts（2003）指出了现在许多学者已经意识到 将社会责任运用到企业采购中去的重要性, 但是文献中提 供了很少达到这一目标的引导。他认为最关键的挑战是如 何让企业知道社会责任对企业内部和外部合作者的重要 性。
有关零售企业供应链管理的文献表明：国内外学者对 零售业供应链管理的研究关注点主要集中在供应链的物 流、信息技术应用、供应链的结构、供应链的评价等供应 链的运作层次, 主要解决的是供应链的运作效率问题。这 些研究孤立地关注供应链经济效益或者集中分析供应链的 某些环节, 忽视了零售企业的特点以及环境、社会与资源 的外部性等问题, 对于零售企业供应链管理理论没有全局 的描述和认识, 还不能为零售企业提供理论指导。同时这 些理论的研究大多集中在经济效益方面, 全球范围内可持 续发展意识的增强使得片面追求经济效益的传统供应链管 理 (SCM) 开始被重新审视。随着企业竞争加剧、公民社 会责任意识增强以及战略管理的兴起, 必须对经济、社会 和环境效益这三重底线进行整体协调, 将可持续发展的理 念引入到供应链管理之中以追求整体效益的最大化。在这 样的背景下, 本文分析了我国零售业供应链管理的现状, 针对存在的问题, 探讨了我国零售业构建可持续供应链管 理体系的策略, 针对我国国情提出零售业可持续供应链管 理未来发展的新趋势和改造实施办法。

\section{3. 零售业的可持续供应链管理}

\section{1 可持续供应链管理的内涵}

英国著名供应链专家 Martin Christopher(1992)认为: 市 场上只有供应链而没有企业, 真正的竞争不是企业和企业 之间的竞争, 而是供应链与供应链之间的竞争; 这就要求 企业在战略考虑中, 不是从单个企业出发, 而是要从供应 链的整体出发, 进行全面的优化和控制, 与上下游企业的 资源共享, 实现可持续的供应链管理, 从而更加灵敏的适 应市场。

可持续供应链管理是可持续发展理念在供应链管理中 的体现。关于可持续供应链管理的概念, 学术界还没有统 一的界定。笔者认为: 可持续供应链管理 (SSCM, sustainable supply chain management）是企业和其所在的供应链从战略 高度系统协调经济、社会和环境效益三重底线, 有效管理 供应链中的物流、信息流和资金流，以期获取长期经济效 益和持久竞争优势。依据这种理念, 在企业经营中, 除了 要考虑经济因素之外, 还要考虑环境和社会两个重要因素。 传统的供应链管理是以整体经济利益最大化为目的, 并没 有考虑社会和环境效益。为了增进整个供应链的效益, 可 持续供应链管理要权衡更广范围的绩效目标, 因此, 供应 链上的企业在传统经济目标之外还要考虑环境和社会的可 持续性。而实现可持续的供应链管理不能是一句空话, 要 结合各个行业的特点进行研究和布局。 


\section{2 零售业的基本特征}

零售业供应链是指零售业主根据客户的需求, 采购不同来 源的货物提供给客户, 以满足客户的需求, 同时获得利润。 零售业供应链的最终目标是通过信息在制造商、分销商、 零售商和顾客之间无缝、迅速流动, 从而实现对各成员资 金流、信息流和物流的高效管理, 降低运营成本, 提高企 业效益, 给消费者带来更多实惠, 同时使企业竞争力得到 增强。由于零售企业供应链呈现单向树状的结构特点, 这 一类供应链的管理在核心内容和管理方法上都有很大的不 同, 主要体现在:

- 以零售企业为主导。随着市场进入买方市场, 在供 应链末端中近距离接触消费者的零售企业凭借其资金、 信息、渠道等优势, 成为整个供应链网络的协调中心, 从而主导供应链。零售企业的主导地位主要表现在零售 企业可以更加自由的选择供应商; 而供应商更多的需要 依赖零售商的销售渠道。

- 典型的拉动式供应链, 即供应链网络完全以消费者 购买为驱动。Roger Blackwell(2000)是最早对零售业供应 链进行全面、系统的研究。他将供应链管理技术应用到 零售业供应链构建中, 认为零售业的供应链是由消费者 驱动的。拉动式供应链模式通常根据用户实际需求来生 产定制化的产品, 由消费者需求来激发最终产品的供给。

- 零售业的供应链有效性和反应性并重。著名的供应 链管理专家 Fisher(1997)认为供应链的设计要以产品为 中心。根据产品的不同市场需求特征, 把产品分为革新 性产品和功能性产品。革新性产品生命周期长, 边际利 润高、需求不稳定; 功能性产品包括人们日常需求的大 众化商品, 边际利润低、有稳定需求。而零售商在经营 的产品, 大多数都可以归为这两类。根据马歇尔 $\cdot \mathrm{L}$. 费舍 尔“基于产品的供应链设计策略”理论, 对于革新性产品 的特性, 在供应链中应当选择反应性供应链, 目的是对 市场需求迅速做出反应。对于功能性产品应当选择有效 性供应链的, 目的是协调物料流和服务流, 使库存最小 化, 最终获得供应链上的制造商和服务提供商的效率最 大化。在零售企业供应链中, 要提供数以万计的最终产 品与服务, 为了实现供应链管理对不同产品能达到较好 的匹配, 其主导的供应链管理必然采用有效性和反应性 并重的策略。

- 随着外国零售业的进入和本土零售企业现代化的不 断迈进, 可持续发展战略逐步纳入到零售企业的长远规 划中。零售业实施可持续供应链管理协调了企业自身利 益和社会整体收益, 是增强企业竞争力的重要途径, 也 是企业可持续发展的战略重点。作为社会影响力不断扩 大的零售企业, 可持续供应链管理代表了包括中国零售
业在内的世界零售企业发展的崭新机遇。

\section{4. 零售业的供应链管理现状}

零售业供应链系统主要包括三个子系统: (1) 零售 商与供应商系统; (2) 零售商内部管理系统; (3) 零售 商与客户关系系统。在整个供应链系统中零售商占有主 导地位, 其应当在经营中实施可持续供应链管理。但是, 在目前我国零售业的经营管理中, 存在许多与可持续供 应链管理不相适应的问题。突出表现在供应链的关系趋 于失衡。这主要是因为虽然大部分零售企业都认识到良 好的供应链关系对于提升核心竞争力的重要性, 并且大 部分企业承诺与供应商等建立稳定、持续、互动的合作 关系, 并依此为基础开展供应链责任的管理实施。但在 根深蒂固的利益观念面前, 零售企业往往会打破供应链 责任的合作基础, 使供应链关系趋于失衡。

\section{1 零售商与供应商系统}

我国的零售商与供应商之间缺乏信任与合作，长期 以来处于利益对立关系, 零售商除了进行超低价采购外, 一般还向供应商索取名目繁多的费用, 甚至干预供应商 的公平竞争, 这些费用加剧了供应商的成本, 使利润在 节点企业间分配中产生了扭曲, 这在一定程度上降低了 整个供应链的竞争力。其次, 费用的收取往往破坏零售 商与供应商之间的合作感情, 甚至促使供应商产生道德 风险, 以降低产品质量来弥补损失, 最终导致稳定的合 作关系难以维持。另外, 零售商接近供应链的最终环节

消费者, 可以很方便地获取市场信息。但是, 许多 零售商出于自身利益的考虑, 把市场信息作为自己的私 有财产。供应商无法获得零售商的库存信息和销售信息, 同样也向零售商封锁商品创新的信息, 最终增加了零售 商与供应商之间的信息成本和商品成本, 降低了整个供 应链的效率。

\section{2 零售商内部管理系统}

零售商内部管理系统的失衡主要体现在对基本员工 的责任一一劳工人权与职业健康上。由于零售业是一个 劳动密集型的行业, 零售业的市场对于零售业人才的需 求尤为紧迫。但各家零售商之间以优厚待遇高薪聘请的 均是中高层次的零售、管理人才。而零售业的一线员工 的劳动强度高、薪酬福利待遇差, 零售业为了节省劳动 成本, 在聘请一线员工的时候很多都是派遣工人, 这些 一线从业人员的年收入一般低于社会平均水平。不仅如 此, 一线员工们基本上没有基本保险等福利, 甚至连节 假日的加班补助都难以到位, 这往往给员工很大的工作 
压力, 影响他们的工作积极性和自信心。许多零售企业 重视质量控制, 重视工作效率及企业效益, 往往忽视了 员工思想、福利、家庭、培训与合理使用等问题, 缺乏 对员工生活的关心, 管理缺乏人情味, 企业内部缺乏和 谐融洽的气氛, 这造成零售业一线员工存在着流动率过 高的现象。

\section{3 零售商与客户关系系统}

零售商与客户关系系统主要体现在保护消费者权益 方面。零售业直接面向消费者, 这能够让其更加灵敏的 适应市场, 从而主导了供应链。但同时由于卖方市场占 有信息优势, 很容易发生道德风险。消费者欺骗消费者 的现象时有发生。零售商损害消费者权益行为主要集中 在三个方面: 一是不实宣传, 损害了消费者的知情权; 或以虚假的清仓、拆迁、停业等事由开展促销活动, 欺 骗消费者。二是价格欺计, 一些零售商以频繁打折、降 价等方式进行促销, 以虚高原价迷惑、欺骗消费者, 扰 乱零售行业的竞争秩序。三是限制消费者合法权益, 零 售商往往规定促销商品不退不换, 或以保留最终解释权 等名义，免除自己的责任，消费者权利受到侵害。

\section{4 频发的社会责任危机}

除了供应链系统之间的失衡外, 一般的零售业并没 有把环境保护和社会责任纳入自己的责任范围之内, 因 此, 零售业在高速增长进程中也受到了激烈的批评 (包 括不太重视环境保护、工作时间长、工资低等缺乏社会 责任感的行为)。长期以来, 零售商基本把“低价销售” 作为其战略核心, 其供应链管理规范的本质就是全方位 地减低成本, 在此基础上, 实现持续的高速增长。这种 以全方位减低成本为核心的传统供应链管理模式使得零 售商必定在社会、环保方面出现种种“不负社会责任”的 现象, 从而必然饱受来自社会各个方面的批评。想确保 供应链管理的可持续性发展, 就要重塑供应链管理, 建 立可持续的供应链管理。

\section{5. 从战略角度重塑零售业供应链管理}

可持续供应链管理的本质特征是集成性、系统性与 协调性的统一, 是物流、商流、信息流的协调, 追逐整 个供应链的成本最小、环境和社会的最优化。将可持续 发展作为一个核心运营问题进行管理, 视为公司运营不 可分割的组成部分, 这是公司识别并处理供应链中各种 取舍问题或者冲突的唯一途径。当然, 要做好零售业的 可持续供应链管理也不是一蹴而就的事情, 需要以下几 个方面来实现:
1、确立可持续供应链管理在零售业供应链中的战略 地位, 明确供应链责任。在零售业供应链中确立可持续 供应链管理的战略地位需要供应链各个主体及时更新管 理理念, 对经济、社会和环境效益这三重底线进行整体 协调, 以整个供应链长期效益的最大化为出发点, 将可 持续性作为总体战略的一部分, 在企业和供应链的全过 程中推行可持续发展的理念, 使之成为供应链所有成员 的自觉行动, 塑造企业可持续发展的形象。零售企业作 为零售业供应链的核心, 要首先调整策略, 重塑企业的 治理结构、管理程序和采购策略。零售商必须放弃原来 过渡追求低价采购和及时供应的方式, 而适度为供应链 责任让出空间, 让供应商有能力、有时间改善社会责任 行为。

2、零售业供应链要根据自己行业特点, 构建可持续 供应链绩效评价体系。在构建绩效评价体系时不但要考 虑供应链各节点企业的合作和同类行业间的竞争, 为供 应链的优化、重组、运行提供相关的客观依据, 而且还 要考虑供应链对外界环境、社会的责任, 为企业实现外 部责任提供必要的指导。目前零售业供应链还没有成熟 的绩效评价体系, 在构建时可以借鉴国内外比较成熟的 可持续供应链管理绩效考核指标。如 ISO14001 环境标 准管理体系 AA100S 利益相关者参与标准、SA8000 社 会责任标准体系等;

3、零售业供应链各主体要信息共享和采购透明化, 方便利益相关者监督。通过信息共享, 一方面可减少减 轻企业业务上的一些环节和工作，如对帐、下订单等; 另一方面, 及时的信息共享机制可以减少牛鞭效应, 使 供应商能够准确、快速、及时地提供零售商所需要的产 品, 达到以信息替代库存的效果, 降低零售业供应链的 成本。同时, 在信息共享条件下, 可以减少机会主义行 为，克服企业之间的相互猜疑;

另外也应该增加供应链的透明度, 把产品的产地、 安全标准等信息标示出来, 充分维护消费者权益, 这有 利于增加供应链各主体之间的互信, 提升供应链的竞争 力。

4、优化零售业供应链, 促进零售产业升级。优化零 售业供应链最重要的一环是研究消费者心理, 转变供应 链模式。零售企业作为零售业供应链上距离消费者最近 的一环, 应当深入研究消费者心理, 了解消费者需求, 为消费者创造价值, 把供应链转变为价值链。其次企业 要与供应商共同, 不断对供应链进行优化。与供应商共 同提高和对供应链的优化主要通过建立有效的激烈约束 机制。有效的激励约束机制是零售业供应链协同运行的 基础, 可以实现企业之间资源的优化配置, 提高整个零 
售业供应链的市场竞争力。

5、加强内部凝聚力, 切实提高员工待遇, 实现人性 化管理, 建立合理的薪酬制度和科学系统的管理体系。 零售商作为零售业供应链中的核心企业, 不仅要做好供 应链中各个外部主体的协调, 还要加强内部整合, 发挥 内部力量的凝聚力, 这突出表现在要调动员工的积极性。 零售业是重要的服务业, 员工尤其是一线员工的服务质 量严重影响消费者的购买行为。这就要求在企业管理中 要实现人性化管理, 充分调动员工的积极性。一方面要 建立合理的薪酬制度。另外一方面要建立科学系统的管 理体系。

在中国的大多数零售企业, 对可持续供应链管理只 限于认识水平, 没有上升到企业整体经营战略, 而且, 可持续供应链应该强调产品生命周期内所有活动的集中 表现, 而不是某一局部或阶段。这就要求供应链中的主 导企业零售商承担更大的责任, 一方面要做好自身的社 会责任, 其次要引导供应链中的其他主体做好供应链责 任。

\section{参考文献(References)}

[1] Craig R.Carter, Dale S.Rogers. A framework of sustainable supply chain management: moving toward new theory. International Journal of Physical Distribution \& Logistics Management, 2008, 38(5):360-387.

[2] Drumwright ME. Socially responsible organizational buying: environmental concern as a non-economic buying criterion. Journal of Marketing,1994,58:1-19

[3] Elkington J. Cannibals. The triple bottom line of the 21 st century. New Society Publishers, 1998

[4] Lamming R., Hampson J. The Environment as a Supply Chain Management Issue. British Journal of Management, 1996(7): 45-62.

[5] Linton J.D., Klassen R., Jayaraman V. Sustainable Supply Chains: an Introduction. Journal of Operations Management, 2007, 25(6):1075-1082.
[6] Marshall L. Fisher. What Is the Right Supply Chain for Your Product?. Harvard Business Review, 1997(3):105-116.

[7] Martin Christopher. Logistics and Supply Chain Management. Pitman Publishing, 1992.

[8] Murphy P.R., Poist R.F., Braunschweig C.D. Management of environmental issues in logistics: current status and future potential. Transportation Journal,1994,34(1):48-56

[9] Roberts S. Supply chain specific? Understanding the patchy success of ethical sourcing initiatives. Journal of Business Ethics,2003,44(2/3):159-170

[10] JIN Xuelian. The retail supply chain management. Enterprise Research, 2004(5):65-66.

[11] Roger Blackwell, The retail reconstruction of supply chain on the new millennium translated by Ji Jianhua, Ren Jianli Zhaoping, etc. , 2000, Shanghai Far East Press

[12] Shen Hou-cai, Tao Qin, Chen Yu-bo. Supply Chain Management: Theory and Method. Chinese Journal of Management Science, 2000, 3(01).

[13] WU Jinfeng. The retail chain supply chain management research (based on the strategic perspective). Reformation \& Strategy, 2007 (3): 27-30.

[14] David Simchi-Levi. Designing and Managing The Supply Chain: Concepts, Strategies and Case Studies. translated by Ji Jianhua, etc. Beijing: China Financial \& Economic Publishing House, 2004: 145-182

[15] Yan Gao-jie. Research on Sustainable Supply Chain Management Based on the Triple Bottom Line. Logistics Technology, 2009, 28(3):114-117.

[16] Xu Zhengyu, Zhu Jinfu, Xie Zhihua. Micro-foundation of Energy Conservation and pollution Alleviation and the Sustainable Supply Chain Management of the Retailers. Chinese Retail Research, 2009, 1(1):77-87. 